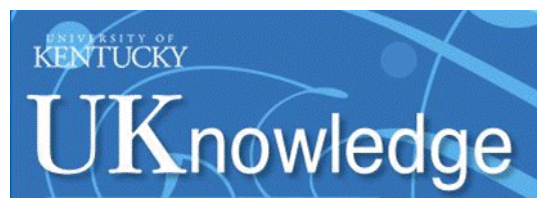

University of Kentucky

UKnowledge

$11-2018$

\title{
Optimal Design of a Switched Reluctance Motor With Magnetically Disconnected Rotor Modules Using a Design of Experiments Differential Evolution FEA-Based Method
}

\author{
Vandana Rallabandi \\ University of Kentucky, vandana.rallabandi@uky.edu \\ Jie $\mathrm{Wu}$ \\ University of Kentucky \\ Ping Zhou \\ ANSYS, Inc. \\ David G. Dorrell \\ University of KwaZulu-Natal, South Africa \\ Dan M. Ionel \\ University of Kentucky, dan.ionel@uky.edu \\ Follow this and additional works at: https://uknowledge.uky.edu/peik_facpub \\ Part of the Electromagnetics and Photonics Commons, and the Power and Energy Commons \\ Right click to open a feedback form in a new tab to let us know how this document benefits you.
}

\section{Repository Citation}

Rallabandi, Vandana; Wu, Jie; Zhou, Ping; Dorrell, David G.; and Ionel, Dan M., "Optimal Design of a Switched Reluctance Motor With Magnetically Disconnected Rotor Modules Using a Design of Experiments Differential Evolution FEA-Based Method" (2018). Power and Energy Institute of Kentucky Faculty Publications. 42.

https://uknowledge.uky.edu/peik_facpub/42

This Article is brought to you for free and open access by the Power and Energy Institute of Kentucky at UKnowledge. It has been accepted for inclusion in Power and Energy Institute of Kentucky Faculty Publications by an authorized administrator of UKnowledge. For more information, please contact UKnowledge@lsv.uky.edu. 


\section{Optimal Design of a Switched Reluctance Motor With Magnetically Disconnected Rotor Modules Using a Design of Experiments Differential Evolution FEA-Based Method}

Digital Object Identifier (DOI)

https://doi.org/10.1109/TMAG.2018.2850744

Notes/Citation Information

Published in IEEE Transactions on Magnetics, v. 54, issue 11.

(C) 2018 IEEE Copyright Notice. "Personal use of this material is permitted. Permission from IEEE must be obtained for all other uses, in any current or future media, including reprinting/republishing this material for advertising or promotional purposes, creating new collective works, for resale or redistribution to servers or lists, or reuse of any copyrighted component of this work in other works."

The document available for download is the authors' manuscript version that is accepted for publication. The final published version is copyrighted by IEEE and will be available as: Rallabandi, J. Wu, P. Zhou, D. G. Dorrell and D.M. Ionel, "Optimal Design of a Switched Reluctance Motor With Magnetically Disconnected Rotor Modules Using a Design of Experiments Differential Evolution FEA-Based Method," in IEEE Transactions on Magnetics, Vol. 54, No. 11, pp. 1-5, Nov. 2018. doi: 10.1109/TMAG.2018.2850744 


\title{
Optimal Design of a Switched Reluctance Motor with Magnetically Disconnected Rotor Modules using a Design of Experiments-Differential Evolution FEA based Method
}

\author{
Vandana Rallabandi ${ }^{1}$, Jie $\mathrm{Wu}^{1,2}$, Ping Zhou ${ }^{3}$, Fellow, IEEE, David G. Dorrell ${ }^{4}$, Senior Member, IEEE, and \\ Dan M. Ionel ${ }^{1}$, Fellow, IEEE \\ ${ }^{1}$ Electrical and Computer Engineering, University of Kentucky, Lexington, KY 40506 USA \\ ${ }^{2}$ Zhengzhou University of Light Industry, Zhengzhou, Henan, China \\ ${ }^{3}$ ANSYS, Inc, Pittsburgh, PA, USA \\ ${ }^{4}$ Discipline of Electrical, Electronic and Computer Eng, University of KwaZulu-Natal, Durban, South Africa
}

\begin{abstract}
Switched reluctance (SR) machines are attractive because they present relatively high efficiency and torque density in spite of lacking permanent magnets. This paper focuses on a two-objective optimization of an external rotor switched reluctance motor with a stator that has concentrated coils and a rotor with magnetically isolated modules. The objectives are minimum loss and mass, and eleven independent dimensionless geometric variables are considered as inputs that affect them. A combined design of experiments (DOE) and differential evolution (DE) approach is proposed. The DOE methodology is used to reduce the search space by eliminating from consideration input variable values leading to poor-performing designs. Following this initial DOE study, an optimization study based on DE is run over the reduced search space, which leads to significant savings in computation time. Furthermore, a directed graph based method for comparing different designs on the Pareto front to rank the best compromise designs is proposed.
\end{abstract}

Index Terms - Switched reluctance motor, multi-objective optimization, design of experiments, differential evolution.

\section{INTRODUCTION}

$\mathbf{S}$ WITCHED reluctance (SR) motors employing rotors with magnetically disconnected modules or segmental rotors are shown to have higher specific torque and efficiency. These machines have a stator with wide main and narrow auxiliary stator teeth (Fig. 1 (a)). Only the main teeth are wound with concentrated coils, as seen in the prototype in Fig. 1 (b)). The auxiliary teeth serve as return paths for the flux. The isolated rotor modules are mounted in a non-magnetic stainless steel frame which has high resistivity (Fig. 1 (c)). Larger specific torque and efficiency, in comparison with conventional SR motors, are obtained because of the shorter flux paths [1], [2]. Flux paths in the aligned and unaligned positions are shown in Figs. 2(a) and 2(b). The shorter flux paths result in an increased difference between aligned and unaligned flux linkages when compared with a conventional SR motor of the same dimensions. The torque is directly proportional to this difference; hence, segmental rotor SR motors have higher torque per ampere as compared with conventional SR motors.

This paper reports on optimal design studies for an external rotor segmental rotor SR motor designed for in-wheel electric vehicles [2]. In this low speed application, most of the losses tend to occur in the copper, leading to reduced efficiency. A higher number of rotor modules can be employed to mitigate this skewed loss distribution. High polarity SR motors have smaller flux-per-pole and consequently rotor and stator core and tooth volumes. This increases the slot area available to the coils, and thus, larger conductor cross-sectional area, leading to smaller resistance and loss, or alternatively, a higher number of ampere-turns resulting in increased specific torque output, can be used, as demonstrated in [3], [4]. The studied machine

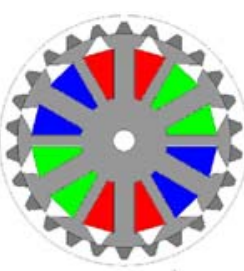

(a)

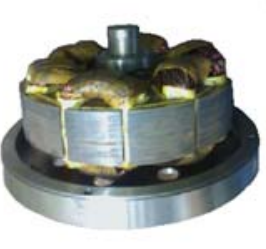

(b)

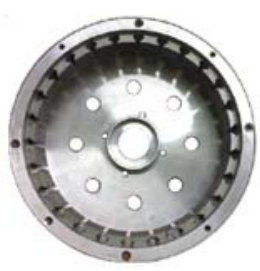

(c)

Figure 1. External rotor SR machine with magnetically isolated rotor modules (a) 2D cross section, (b) Wound stator and (c) Segmental rotor with the modules placed in a stainless steel frame.

has 26 rotor modules and 12 stator teeth as shown in Figs. 1(a) and 1(b).

\section{Optimization Problem Formulation AND Finite ELEMENT ANALYSIS}

The aim of this work is to develop an optimized design of a segmental rotor SR motor. The loss, including copper and core loss, and active mass, are to be minimized. These objectives are functions of the machine's geometrical parameters, and in this context, eleven dimensionless independent variables, which are inputs in the optimization study, are identified and listed in Table I. A model of the machine which accepts dimensional geometric variables as inputs is developed in ANSYS/Maxwell which is employed for the finite element (FE) studies. A time transient external circuit coupled analysis with the phase current waveform defined for all the studied designs by specifying the peak current, conduction period, rise and fall times, calculated from the inductance and drive voltage is used. Quantities evaluated in the FE solution include pyrighted by IEEE and available as: V. Rallabandi, J. Wu, P. Zhou, D. G. Dorrell and D. M. Ionel, "Optimal Design of a Switched Reluctance Motor With Magnetically Disconnected Rotor Modules Using a Design of Experiments Differential Evolution FEA-Based Method," in IEEE Transactions on Magnetics, Vol. 54, No. 11, pp. 1-5, Nov. 2018. doi: 10.1109/TMAG.2018.2850744 (c)2018 IEEE Copyright Notice. "Personal use of this material is permitted. Permission from IEEE must be obtained for all other uses, in any current or future media, including reprinting/republishing this material for advertising or promotional purposes, creating new collective works, for resale or redistribution to servers or lists, or reuse of any copyrighted component of this work in other works." 
Table I

INPUT GEOMETRIC VARIABLES CONSIDERED IN THE STUDY, AND THEIR RANGES FOR THE INITIAL SCREENING DOE ANALYSIS. THE RANGES UPDATED FROM RESULTS OF THE DOE ANALYSIS AND USED FOR SUBSEQUENT OPTIMIZATION STUDIES ARE ALSO SHOWN.

\begin{tabular}{|c|c|c|c|c|c|}
\hline $\begin{array}{l}\text { Dimensionless } \\
\text { variable }\end{array}$ & $\begin{array}{l}\text { Initial } \\
\text { minimum }\end{array}$ & $\begin{array}{l}\text { Initial } \\
\text { maximum }\end{array}$ & $\begin{array}{l}\text { Updated } \\
\text { minimum }\end{array}$ & $\begin{array}{l}\text { Updated } \\
\text { maximum }\end{array}$ & Prototype \\
\hline Split ratio, ratio of rotor outer diameter (OD) to rotor inner diameter (ks) & 0.80 & 0.95 & 0.85 & 0.95 & 0.85 \\
\hline Stator pole arc to pole pitch ratio (kspa) & 0.70 & 0.95 & 0.90 & 0.95 & 0.9 \\
\hline Main stator tooth width to stator pole pitch ratio (ks1) & 0.18 & 0.26 & 0.18 & 0.22 & 0.21 \\
\hline Aux stator tooth width to stator pole pitch ratio (ks2) & 0.09 & 0.15 & 0.09 & 0.15 & 0.13 \\
\hline Main stator tooth tip height to stator outer radius ratio (ktip1) & 0.07 & 0.14 & 0.07 & 0.14 & 0.1 \\
\hline Aux stator tooth tip height to stator outer radius ratio (ktip2) & 0.07 & 0.14 & 0.12 & 0.14 & 0.12 \\
\hline Main stator tooth tip width to stator pole pitch ratio (kwtip1) & 0.04 & 0.12 & 0.04 & 0.06 & 0.04 \\
\hline Aux stator tooth tip width to stator pole pitch ratio (kwtip2) & 0.04 & 0.12 & 0.04 & 0.07 & 0.04 \\
\hline Stator back iron width to stator outer radius ratio (kby) & 0.30 & 0.60 & 0.30 & 0.60 & 0.32 \\
\hline Ratio of rotor pole arc at rotor ID to rotor pole pitch (krpa1) & 0.70 & 0.95 & 0.70 & 0.95 & 0.85 \\
\hline Ratio of rotor pole arc at OD to rotor pole pitch (krpa2) & 0.20 & 0.50 & 0.20 & 0.50 & 0.32 \\
\hline
\end{tabular}

electromagnetic torque, core and copper loss. The active mass is computed from the geometric parameters. Constants in this optimization study are the outer diameter and operating current density. The axial length for each design is modified to ensure that all the studied candidates provide the same torque. An optimization algorithm employing a combination of Design of Experiments (DOE) and differential evolution (DE) is used.

At least two electrical cycles are required to be run for steady state core loss estimation, and accordingly, each simulation study requires four minutes to run. For the case of several hundred candidate designs being analyzed, large computational times are required to complete the optimization study.

The time domain decomposition method (TDM) within ANSYS is employed to reduce the solution time. Conventional FE tools tend to solve time steps sequentially, while in the TDM approach, multiple time steps are processed simultaneously. This approach reduces the computational time by half. In the transient solvers, the TDM model divides the solution time into several subdivisions, and the time steps constituting one solution are solved simultaneously. Each subdivision is solved sequentially, and the solutions obtained at the last time step in the current subdivision are used as initial conditions for the following one. The smaller the number of subdivisions, the larger the number of time steps that are solved simultaneously, and consequently, significant reductions in solution time are obtained. For a computer with a large number of cores, the number of subdivisions can be made very small, and order of magnitude reductions in simulation time are observed [5]. In this study, a 10-core computer was used, and the solution time was reduced to half when TDM was employed.

The number of candidate designs that need to be studied to find an optimum solution if all eleven input designs variables are considered is very large. In some works, screening DOE runs such as fractional factorial and Plackett - Burman are employed to identify which of the input variables have a significant impact on the objectives within the search space [6]-[8]. This paper proposes a methodology in which the DOE approach is used to identify ranges of the input geometric variables that are likely to lead to better performing designs. This narrowing down of the search space would result in

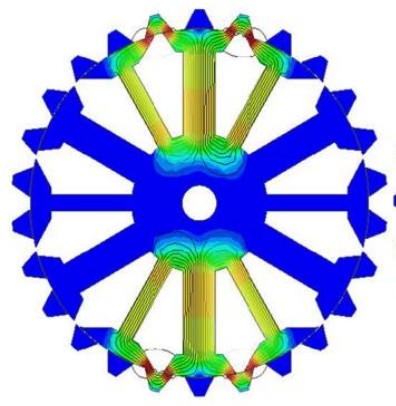

(a)

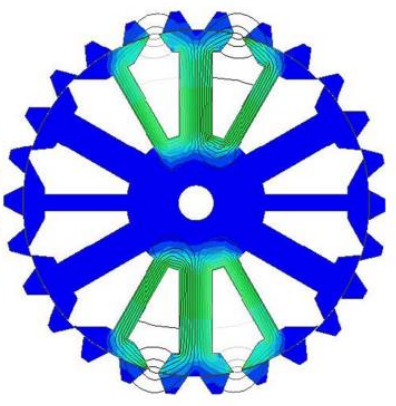

(b)
Figure 2. Flux paths in a SR motor with isolated rotor modules at (a) the aligned position, and (b) The unaligned position.

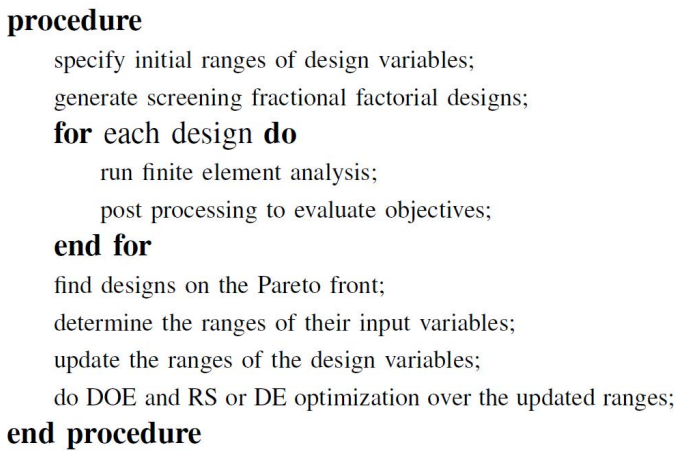

Figure 3. Procedure for the proposed DOE-algorithm. Initial studies are conducted over a wide search space, designs on the Pareto front identified, and the ranges of independent variables updated.

a reduced number of computations required to identify the optimum solutions. Differential evolution is then employed over the updated search space.

\section{DESIGN OF EXPERIMENTS}

The DOE approach was used in this paper to determine the ranges of the independent variables resulting in low mass and loss designs with a view to reducing the computational time for optimization studies with a large number of design variables. The proposed algorithm starts with multiple fractional factorial DOE designs over a wide search space. A narrower search 


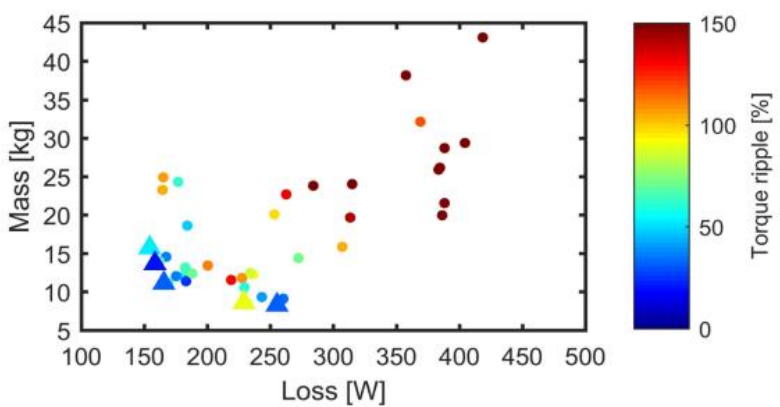

(a)

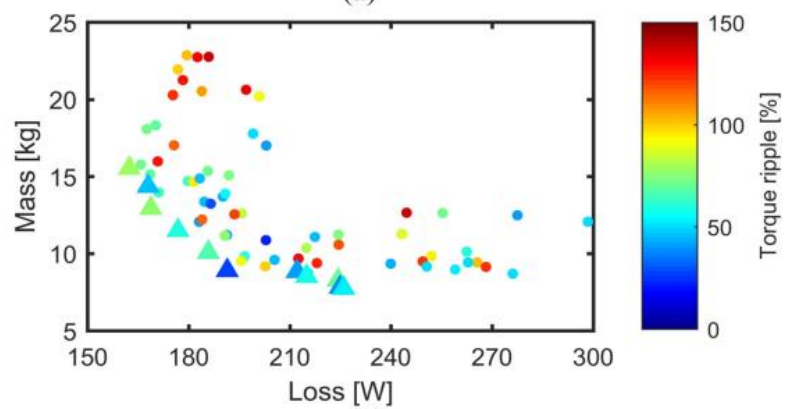

(b)

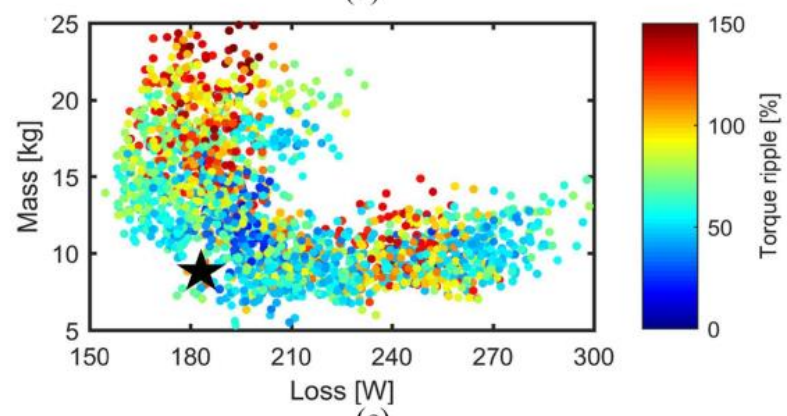

(c)

Figure 4. Mass versus loss for different designs obtained from (a) the initial screening DOE runs. Designs with very high mass and loss are eliminated from further consideration. (b) Mass versus loss for the "second generation" DOE, with 72-runs and ranges of independent variables derived from the high performing designs of the initial screening DOE and (c) response surface design generated from the DOE. The black asterisk marks the prototype machine.

space is derived from a study of the range of input variables leading to better performing designs in the screening DOE studies as shown in Fig. 3, and Table I. Design of experiments and response surface (RS) with a larger number of runs or DE-based optimization studies can be conducted to identify the best-compromise designs over the updated and narrower search space.

The results of the initial DOE runs are seen in Fig. 4(a). For eleven design variables, 3-separate fractional factorial experiments with a total of 48 initial runs were conducted. It is seen that some combinations of input geometric variables result in designs that produce the target torque but with very large mass and loss. The range of independent variables for optimization studies using DOE/RS and DE was selected from the Pareto front constructed for the designs in Fig. 4(a).

A DOE based study, with 72-designs, capable of identifying the main effects and two-way interactions with the ranges of variables updated to those in Table I was then conducted, and the results are seen in Fig. 4(b). All the designs represented produce the same torque, albeit they require and incur different active masses and losses. A response surface model considering all the main and two-way interaction terms was developed, and is shown for 2048-designs in Fig. 4(c), and the performance of the prototype machine is marked with a filled asterisk. It may be observed from this figure that the prototype motor was designed for a low mass, and loss reductions can be achieved, but at the cost of higher mass. It may be noted that the RS model simply populates the design space using results from the DOE, but does not advance the Pareto front.

\section{Differential Evolution}

Differential Evolution was used to find the optimum design over the updated narrower range found from the DOE approach. The DE included twenty generations, with ten individuals per generation. The stopping criteria used were related to the maximum number of function evaluations, number of generations and variation of objectives from generation to generation. This resulted in a total of 210-candidate designs, and 15-designs on the Pareto front are identified. It is seen that the DE identifies better performing designs as compared with the DOE (Fig. 5). The reason may be that the DE employs 210-evaluations, in addition to the initial 48-DOE screening runs, while the DOE has only 72.

Referring to Fig 5, it may be seen that the Pareto front includes low loss, high mass designs, a central part which contains the best compromise designs, and a horizontal part with machines having the least mass. The $2 \mathrm{D}$ cross section of the design which achieves the target torque with minimum loss is seen in Fig. 6(a). One of the low mass designs was selected for prototyping because the intended application is cost sensitive and low mass is preferred. Further, the higher losses also help establish the thermal limitations. The geometric properties of the design selected for prototyping are listed in Table I, and its 2D cross section is seen in Fig. 6(b).

The central part of the Pareto front includes best compromise designs, which meet both objectives of low mass and loss, and the range of input design variables for these designs in seen in Fig. 7. This combination of design parameters would lead to designs that achieve a balance between loss and mass. The performance of the prototype as calculated from FEA is compared with experimental measurements based on lab tests on a dynamometer and results are seen in Fig. 8. A satisfactory agreement between experiments and simulations is observed.

Following the optimization study using DE, a method to systematically compare designs is proposed. This method allots scores and ranks designs based on a directed graph, constructed by representing each design with co-ordinates corresponding to the values of its objective functions as shown in Fig. 9. Arrows in the directed graph point towards designs with smaller co-ordinates. The score of each candidate design is evaluated by taking normalized weighted sums of the scores of other designs. The weight is calculated using the difference between the co-ordinates. This difference, if found to be against the direction of the arrows, leads to the corresponding 


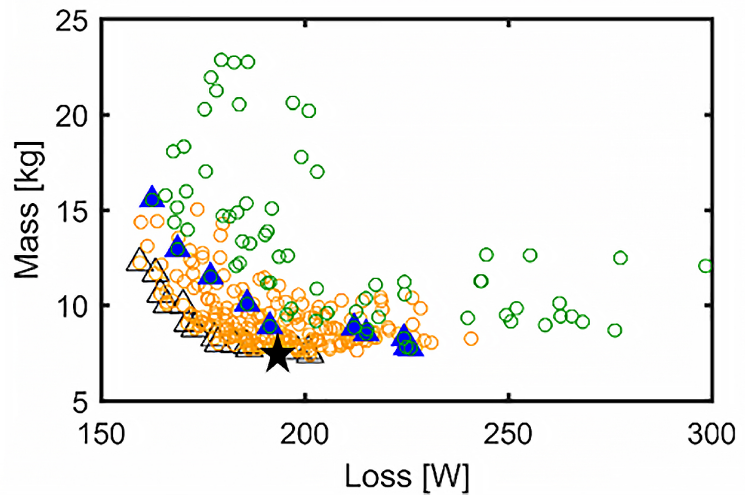

Figure 5. Designs on the Pareto front from the DOE and DE studies. The Pareto fronts of the DOE and DE studies are represented by filled and unfilled triangles respectively. The DE identifies better performing designs as compared with the DOE method. The filled asterisk marks the prototype.

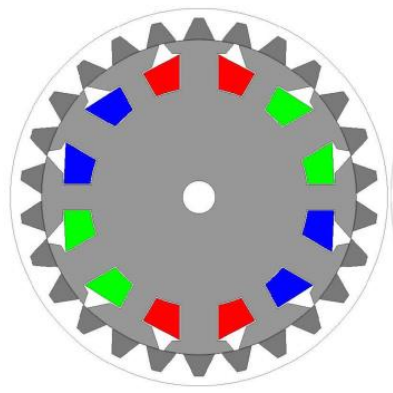

(a)

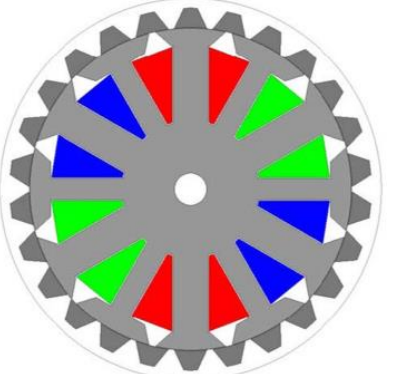

(b) (a)

Figure 6. 2D cross section of the designs on the extreme tips of the Pareto (a) Design with the least loss and (b) the prototyped design.

weights being set at zero. The scores are evaluated by the solution of an equation of the type $A x=x$. Designs with higher score are considered better. This method provides a quantitative base for comparing designs on the Pareto front and additional benefits in the multi-generation selection process. Furthermore, weighing factors, depending on which objective is more important, can also be included and this may be used to study different scenarios.

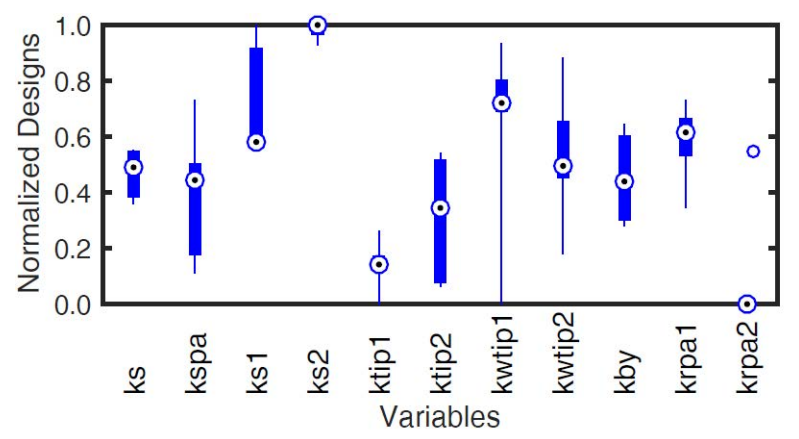

Figure 7. The variation of normalized geometric parameters for the designs on the central part of Pareto front obtained from the DE algorithm, with 0 corresponding to the minimum value, and 1 to the maximum.

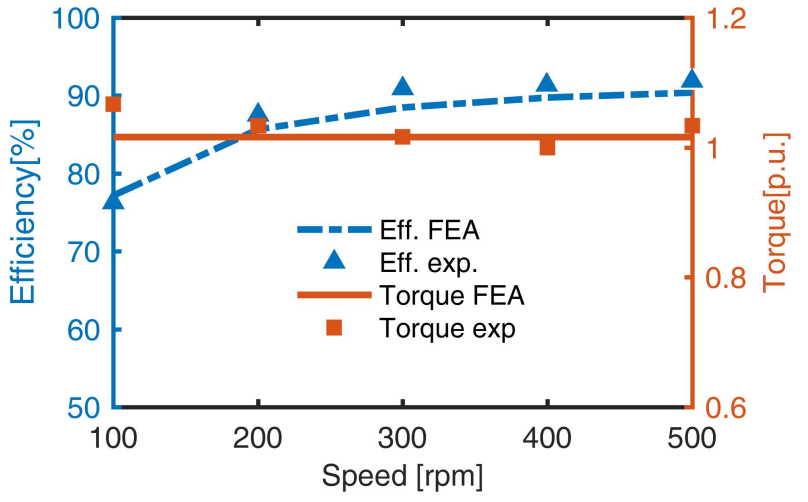

Figure 8. Measured and calculated efficiencies and torque output of the prototype machine. A satisfactory agreement throughout the operating speed range is observed.

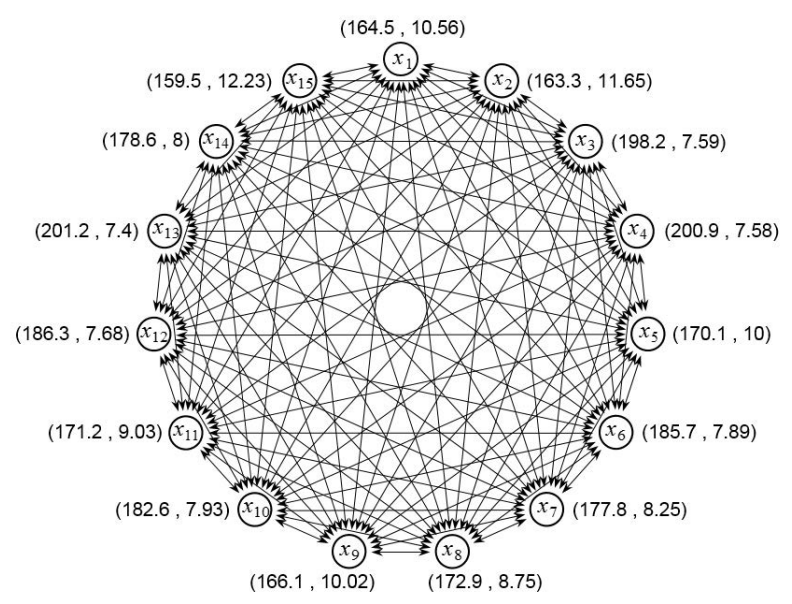

Figure 9. Schematic illustration of the proposed method for systematically selecting best compromise designs from the Pareto front.

\section{CONCLUSION}

This paper reports on systematic optimization studies for an external rotor segmental rotor switched reluctance motor. Eleven independent input geometric variables are considered, and a combined Design of Experiments and Differential Evolution based method is employed to identify designs that produce the target torque with minimum loss and mass. Larger ranges of the independent variables are employed in the initial DOE runs. The ranges in which high performing designs are likely to lie are identified, and used for subsequent DE and DOE/RS runs. This results in a significantly smaller search space and consequently fewer number of design evaluations runs, and leading to saving in computational time. The DE study also distinguishes the features of high performing designs.

\section{ACKNOWLEDGMENT}

The support of University of Kentucky, the L. Stanley Pigman endowment and the SPARK program, and of ANSYS Inc. is gratefully acknowledged. 


\section{REFERENCES}

[1] B. C. Mecrow, E. A. El-Kharashi, J. W. Finch, and A. G. Jack, "Segmental rotor switched reluctance motors with single-tooth windings," IEE Proceedings - Electric Power Applications, vol. 150, no. 5, pp. 591-599, Sept 2003.

[2] S. P. Nikam, V. Rallabandi, and B. G. Fernandes, "A high-torque-density permanent-magnet free motor for in-wheel electric vehicle application," IEEE Transactions on Industry Applications, vol. 48, no. 6, pp. 2287-2295, Nov 2012.

[3] P. C. Desai, M. Krishnamurthy, N. Schofield, and A. Emadi, "Novel switched reluctance machine configuration with higher number of rotor poles than stator poles: Concept to implementation," IEEE Transactions on Industrial Electronics, vol. 57, no. 2, pp. 649-659, Feb 2010.

[4] J. D. Widmer and B. C. Mecrow, "Optimized segmental rotor switched reluctance machines with a greater number of rotor segments than stator slots," IEEE Transactions on Industry Applications, vol. 49, no. 4, pp. 1491-1498, July 2013.

[5] P. Zhou, B. He, C. Lu, D. Lin, and N. Chen, "Transient simulation of electrical machines using time decomposition method," in 2017 IEEE International Electric Machines and Drives Conference (IEMDC), May 2017, pp. 1-6.

[6] P. Zhang, G. Y. Sizov, D. M. Ionel, and N. A. O. Demerdash, "Establishing the relative merits of interior and spoke-type permanent-magnet machines with ferrite or ndfeb through systematic design optimization," IEEE Transactions on Industry Applications, vol. 51, no. 4, pp. 2940-2948, July 2015.

[7] P. D. Barba, F. Dughiero, M. Forzan, and E. Sieni, "Magnetic design optimization approach using design of experiments with evolutionary computing," IEEE Transactions on Magnetics, vol. 52, no. 3, pp. 1-4, March 2016.

[8] X. Zhu, B. Yan, L. Chen, R. Zhang, L. Quan, and L. Mo, "Multi-objective optimization design of a magnetic planetary geared permanent magnet brushless machine by combined design of experiments and response surface methods," IEEE Transactions on Magnetics, vol. 50, no. 11, pp. 1-4, Nov 2014

Vandana Rallabandi (M'17) is a Post-doctoral Researcher in the SPARK Laboratory, Electrical and Computer Engineering Department, University of Kentucky, Lexington, KY. Prior to this, she was a Research Engineer at the General Electric (GE) Global Research Center in Bangalore, India. She obtained the Masters and Ph.D. degrees at the Indian Institute of Technology Bombay, India. She has published over forty journal and conference proceedings papers, including three that received awards from IEEE, IET, and ICRERA, respectively, co-authored four book chapters, and has more than five invention disclosures and patent pending applications. She has been a reviewer for IEEE transactions on Industry Applications, Energy Conversion, Power Electronics, Industrial Electronics and Magnetics, IET Electric Power Applications and Electric Power Components and Systems. Her areas of work include electric machines, power electronics drives, renewable energy devices and systems, energy storage, and power systems.
David G. Dorrell received the B.Eng. (Hons.) degree in electrical and electronic engineering from the University of Leeds, Leeds, U.K., in 1988; the M.Sc. degree in power electronics engineering from the University of Bradford, Bradford, U.K., in 1989; and the Ph.D. degree in engineering from the University of Cambridge, Cambridge, U.K., in 1993. He is currently a Professor of electrical machines with the University of KwaZulu-Natal, Durban, South Africa, a post he took up in late 2015. He has held lecturing positions at Robert Gordon University, Aberdeen, UK and the University of Reading, Reading, UK. He was a Senior Lecturer at the University of Glasgow, Glasgow, U.K., for several years. In 2008, he was a Senior Lecturer at the University of TechnologySydney, Sydney, Australia, and He was promoted to an Associate Professor in 2009. His is also an Adjunct Associate Professor with the National Cheng Kung University, Tainan, Taiwan. His research interests include the design and analysis of various electrical machines, and also renewable energy systems. Dr. Dorrell is a Chartered Engineer in the U.K., and a fellow of the Institution of Engineering and Technology.

Dan M. Ionel (M'91-SM'01-F'13) received the M.Eng. and Ph.D. degrees in electrical engineering from the Polytechnic University of Bucharest, Bucharest, Romania. His doctoral program included a Leverhulme Visiting Fellowship at the University of Bath, Bath, U.K. He was a Post-Doctoral Researcher with the SPEED Laboratory, University of Glasgow, Glasgow, U.K.

He is currently Professor of Electrical Engineering and the L. Stanley Pigman Chair in Power with the University of Kentucky, Lexington, KY, where he also serves as the Director of the Power and Energy Institute of Kentucky (PEIK) and of the SPARK Laboratory. He previously worked in industry, most recently as a Chief Engineer with Regal Beloit, Corp., Grafton, WI, USA, and, before that, as the Chief Scientist for Vestas Wind Turbines. Concurrently, he also was a Visiting and Research Professor at the University of Wisconsin and Marquette University, Milwaukee, WI, USA. He contributed to technology developments with long lasting industrial impact, holds more than thirty patents, and published more than two hundred technical papers, including four that received IEEE awards.

Dr. Ionel was the inaugural Chair of the IEEE Industry Applications Society Renewable and Sustainable Energy Conversion Systems Committee and an Editor of the IEEE TRANSACTIONS ON SUSTAINABLE ENERGY. $\mathrm{He}$ is the Editor in-Chief of the Electric Power Components and Systems Journal, the Past Chair of the IEEE Power and Energy Society Electric Motor Subcommittee, and was the General Chair of the IEEE 2017 Anniversary Edition of the International Conference on Electrical Machines and Drives.
Jie Wu is an Assistant Professor of Electrical Engineering at Zhengzhou University of Light Industry, Zhengzhou, China. Since 2017 through 2018, he served as Visiting Professor in the SPARK Laboratory, Department of Electrical and Computer Engineering, University of Kentucky, Lexington, KY, USA. Dr. Wu previously worked at Hubei University of Technology, Wuhan, China. He received the M.Eng. degree from Hubei University of Technology, Wuhan, China, in 2005, and the Ph.D. degree from VSB Technical University of Ostrava, Czech Republic, in 2012, respectively. He contibuted to the AC flux control technology in hybrid excitation machine, holds five patents, and published more than forty papers. His expertise in electric power engineering includes electric machines, power electronic drives, and wireless power transfer. 